\title{
SOCIAL BONDS AND GENETIC TIES: KINSHIP, ASSOCIATION AND AFFILIATION IN A COMMUNITY OF BONOBOS (PAN PANISCUS)
}

\author{
by \\ G. HOHMANN ${ }^{1,2)}$, U. GERLOFF ${ }^{3)}$, D. TAUTZ ${ }^{3)}$ and B. FRUTH ${ }^{1,4)}$ \\ ( ${ }^{1}$ Max-Planck-Institutfür Verhaltensphysiologie,D-82319 Seewiesen, Germany; \\ ${ }^{3}$ Zoologisches Institut der Ludwig-Maximilians Universität, D-80333 München, Germany)
}

(Acc. 18-I-1999)

\begin{abstract}
Summary
Studies of captive populations of bonobos suggest that females are more gregarious than males. This seems to contradict assumed sex-differences in kinship deriving from a speciestypical dispersal pattern of female exogamy and male philopatry. Here we present data on spatial associations and affiliative relations among members of one wild community (Eyengo) for which genetic relationships were identified by analysing mitochondrial and nuclear DNA. Our data from Lomako confirm the existence of spatial associations among resident females. In addition, they reveal strong social bonds between males and females. While most female-female associations did not last longer than one field season, long-term associations occurred predominantly between mixed-sex dyads and involved both close kin and unrelated individuals. Differences in social grooming appeared to be related to patterns of spatial association rather than to kinship. It is suggested that under natural conditions social organisation of bonobos is characterised by strong inter-sexual bonds. Males may benefit from bonding with females by increased reproductivesuccess via rank acquisition. For females benefits may derive from inclusive fitness and reduced food competition. Preliminary evidence suggests that females also may benefit from protection by resident males against male intruders.
\end{abstract}

2) Corresponding author; e-mail address: hohmann@eva.mpg.de

4) We are grateful to the Ministère de l'Education Nationale, Respublique Democratique du Congo for permission to conduct fieldwork at Lomako; W. Wickler, the Max-Planck-Society and the DFG for financial support; W.C. McGrew and L.F. Marchant and an anonymous reviewer for discussions and helpful comments on earlier drafts of the manuscript; J. Lamprecht and H. Hofer for statistical advice; A. Türk and B. Knauer for editorial work and B. Hartung for assistance in the lab. Particular thanks are due to W. Wickler, I. EiblEibesfeldt, D. Ploog and G. Neuweiler for unfailing support and assistance. 


\section{Introduction}

Most diurnal primates form groups of relatively stable size and composition. Protection from predation and infanticide are considered to be major forces responsible for living in permanent groups (van Schaik, 1983). Transfer of single individuals between groups occurs regularly but is usually biased to one sex and often restricted to a particular age. Under certain conditions, spatial associations between group members may become fluid in the way that groups split into subunits (parties) of changing size and composition. Individuals who have the choice to be in different parties are expected to join those where fitness returns are highest. Since benefits may derive from association with close kin (Hamilton, 1964), it seems likely that in species with a fission-fusion system, individuals prefer to travel with kin. At Gombe, high association indices among female chimpanzees (Pan troglodytes) were found to correspond with kinship (Goodall, 1986) but at another site (Kibale) chimpanzees did not preferentially travel with maternal kin (Goldberg \& Wrangham, 1997). Bonobo (Pan paniscus) associations seem not to follow lines of kinship. Although direct behavioural observations are scarce, there is evidence that females migrate, and so in a community females are not expected to be closely related (Kano, 1982). However, females often travel with both females and males. While aggregations of females are thought to reflect affiliative relations (Parish, 1996) and alliance formation against male harassment (Wrangham, 1986), male-female associations are usually linked to the alleged prolonged estrus of females (Turke, 1984; Thompson-Handler et al., 1984; Szalay \& Costello, 1991; Kano, 1992). Alternatively, Wrangham (1986) suggested that females may associate with males in order to gain protection from male harassment. If relationships between the sexes are based primarily on sexual attraction, male-female associations should mainly involve unrelated individuals. Protection from harassment by conspecifics, however, could be provided by any or all males, independent of their genetic relationship to a female.

Studies of dwarf mongoose (Rood, 1990), lion (Grinnell et al., 1995) and olive baboon (Packer, 1977) show that cooperation and affiliation do not require a high degree of genetic relatedness. The general assumption that affiliative relations seen in female bonobos are not based on kinship is supported by genetic analyses of matrilinear relations (Hashimoto et al., 1996). However, it may be premature to conclude that resident females 
have no opportunity to interact with female relatives. In chimpanzees, males are philopatric and females typically transfer. However, the proportion of females who leave their natal community ranges from about $100 \%$ in Mahale to less than $15 \%$ in Gombe (Nishida et al., 1990; Goodall, 1986). As a consequence, the average relatedness of resident females is expected to vary across populations.

Corresponding data from bonobos are not yet available. Findings on feeding ecology suggest that pressure on female bonobos to transfer may be lower than in chimpanzees. First, White \& Wrangham (1988) found that the food patches available to bonobos are larger than those available to chimpanzees. Second, bonobos consume substantial amounts of herbs that are highly abundant throughout the year (Badrian \& Malenky, 1984). Accordingly, any feeding competition between residents is likely to be scramble rather than contest. Given such less intense competition, dispersal by females is expected to be conditional (van Schaik, 1989). Emigration probably depends on a female's social status, on the rank of her mother or on the number of potential competitors. For daughters with high ranking mothers it could be beneficial to remain in their natal community while those of low ranking mothers may gain from transfer (Pusey, 1980; Pusey et al., 1997).

In this study we use data from a community of bonobos on genealogy based on analyses of mitochondrial and nuclear DNA markers. This genealogy allows to infer which individuals are genetically closely related and which are not. This information is then used to assess to what extent spatial associations and affiliative relations between mature males and females are based on genetical ties.

\section{Methods}

\section{General information}

Since 1990, members of the Eyengo community inhabiting the eastern part of the Lomako study site, Democratic Republic of Congo (formerly Zaïre), are observed in an ongoing research project (McGrew et al., 1996). Between 1993 and 1996 the community comprised an average of 12.8 (range: 10-14) males and 22.0 (range: 20-23) females. More information on the composition and demographic changes of the Eyengo community is given in Fig. 1. Community members were identified by disfigured limbs, morphology of sexual swellings, pigmentation of testes and other phenotypic traits. Age estimates of animals born before this study were based on body size, morphological criteria and behaviour. Separation 


\begin{tabular}{|c|c|c|c|c|c|c|}
\hline & 1991 & 1992 & 1993 & 1994 & 1995 & 1996 \\
\hline \multirow{2}{*}{\multicolumn{7}{|c|}{$\begin{array}{l}\text { male: } \\
\text { Max }\end{array}$}} \\
\hline \multirow{2}{*}{\multicolumn{7}{|c|}{$\begin{array}{l}\text { Mlax } \\
\text { Planck }\end{array}$}} \\
\hline & & & & & & \\
\hline \multicolumn{7}{|l|}{ Karl } \\
\hline \multicolumn{7}{|l|}{ Samuel } \\
\hline \multirow{2}{*}{\multicolumn{7}{|c|}{ Renki }} \\
\hline \multicolumn{3}{|l|}{ Pink } & & & & \\
\hline \multicolumn{7}{|l|}{ Volker } \\
\hline \multicolumn{7}{|l|}{ female: } \\
\hline \multicolumn{7}{|l|}{ Viola } \\
\hline \multicolumn{7}{|l|}{$\begin{array}{l}\text { Vasco } \\
\text { Monalisa }\end{array}$} \\
\hline \multicolumn{7}{|l|}{$\begin{array}{l}\text { Monalisa } \\
\text { Leo }\end{array}$} \\
\hline \multirow{2}{*}{\multicolumn{7}{|c|}{$\begin{array}{l}\text { Ndunge } \\
\text { Ndoki }\end{array}$}} \\
\hline \multirow{2}{*}{\multicolumn{7}{|c|}{$\begin{array}{l}\text { Ndoki } \\
\text { Senufo }\end{array}$}} \\
\hline & & & & & & \\
\hline \multicolumn{7}{|l|}{ Ufo } \\
\hline \multicolumn{7}{|l|}{ Nuba } \\
\hline \multicolumn{7}{|l|}{$\begin{array}{l}\text { Lorle } \\
\text { Alison }\end{array}$} \\
\hline \multicolumn{7}{|l|}{$\begin{array}{l}\text { Alison } \\
\text { Ela }\end{array}$} \\
\hline \multicolumn{7}{|l|}{ Vanessa } \\
\hline \multicolumn{7}{|l|}{ Virginia } \\
\hline \multicolumn{7}{|l|}{ Seka } \\
\hline \multicolumn{7}{|l|}{ Lolema } \\
\hline \multicolumn{7}{|l|}{$\begin{array}{l}\text { Merit } \\
\text { Geraldine }\end{array}$} \\
\hline \multicolumn{7}{|l|}{ Lea } \\
\hline \multicolumn{7}{|l|}{ Neuweiler } \\
\hline \multicolumn{7}{|l|}{ Zora } \\
\hline \multicolumn{7}{|l|}{ Zulu } \\
\hline $\begin{array}{l}\text { Tabita } \\
\text { Tagore }\end{array}$ & & & & & $\cdots 1$ & \\
\hline Tanos & & & & & & \\
\hline Gina & & & & & & \\
\hline Lolo & & & & & & \\
\hline $\begin{array}{l}\text { Kamba } \\
\text { Mongo }\end{array}$ & & & & & & \\
\hline Andromeda & & & & & & \\
\hline Bhagmati & & & & & & \\
\hline Luna & & & & & & \\
\hline Amy & & & & & -1 & \\
\hline
\end{tabular}

Fig. 1. Composition and demography of the Eyengo community. Solid lines refer to adolescent and adult members, dotted lines to immatures (infants, juveniles). Names of infants are indented and follow their mothers' names. Names in italics refer to individuals for whom genetic data are not yet available. Vertical bars indicate the approximate time of disappearance of residents, arrows continuing presence. 
of immatures (infants and juveniles) from matures (adolescent and adults) follows the classification used by Hashimoto (1997). To distinguish between adult and adolescent females, body size, length of the mammillae and cyclic changes of genital swellings were used; adult males were distinguished from adolescent males by body size, body proportions and testes size. Records from individuals known since the onset of our project in 1990 suggest that these criteria provide fairly reliable indicators for age assessments. However, because of the inter-individual variation we can not rule out that in some cases assignments to the two age classes were not always correct.

\section{Genetic analyses}

DNA was extracted from faecal samples taken shortly after deposition from unequivocally identified individuals. Samples were transferred into ethanol and stored under ambient temperature for up to several years. DNA extraction and typing was done as described by Gerloff et al. (1995) and with the chelex extraction method (Estroup et al., 1996). Usually, two to five extractions were carried out per faecal sample and up to seven samples were analysed per individual. After extraction, the presence of DNA was confirmed through PCR amplification of part of the mitochondrial D-loop. Extracts producing a visible band on an $0.8 \%$ agarose gel were used for further investigations. To assess the genetic relationships in the study community, we used data from five microsatellite loci originally described for humans (Gyapay et al., 1994) as well as sequencing mitochondrial D-loops for most members of the community (Gerloff et al., in review). Detailed information on the genetic analyses and the evaluations of kinship are published elsewhere (Gerloff et al., 1999). Parentoffspring relationships were assigned when two individuals shared at least one allele at each microsatellite locus and if they had an appropriate age difference. For mother-offspring relationships, we used the sharing of mitochondrial lineage as additional criteria. Potential fathers were identified by subtracting the maternal alleles from the genotype of a child and matching the remaining alleles with the males in the group.

\section{Association patterns}

Data are from four field seasons (1993-1996) each lasting between 5 and 7 months. Calculation of spatial association is based on the frequency that any two individuals were in the same party. These data were extracted from 774 records of party composition when all members were positively identified. Since aggregations at nesting sites may be larger and so less variable (Fruth \& Hohmann, 1994), samples from nest sites were excluded from this analysis. In order to make data points relatively independent, only one record of party composition per day was used resulting in a reduced data set of 255 party size records. Records from each field season were lumped and analysed separately from records of other field seasons. Indices for dyadic associations were calculated with a Fortran version of a randomisation test (Noreen, 1989) written by J. Lamprecht (1985) and H. Hofer using a RAN2 randomisation generator (Press et al., 1992). The frequency of party-attendance of a certain individual $\left(p_{\mathrm{i}}\right)$ was calculated by dividing the number of records when the individual was present $\left(n_{\mathrm{i}}\right)$ through the total number of records of party size $(N)$. The expected value $\left(p_{\mathrm{ij}} \exp \right)$ that two given individuals ( $\mathrm{i}$ and $\mathrm{j}$ ) attended the same party was calculated by multiplication of the observed attendances of both individuals $\left(p_{\mathrm{i}} \times p_{\mathrm{j}}\right)$. Values of random associations (RA) were computed by running 1000 random, uniformly distributed trials for 
each individual of a given dyad. The simulation showed how often an observed association (OA) can be expected by chance. Using statistically significant deviations from random associations ( $p<0.05$, two tailed), dyads were assigned to one of the following three classes: Close associates $(\mathrm{OA}>\mathrm{RA})$, random associates $(\mathrm{OA}=\mathrm{RA})$, 'separatists' $(\mathrm{OA}<\mathrm{RA})$.

\section{Grooming}

Data on social grooming came from ad libitum sampling and focal observations. We defined the following terms: Grooming episode refers to the period one individual (A) groomed another individual (B). When a change in direction (B groomed A) occurred, a new episode was scored. Grooming bout refers to the total of all episodes exchanged continuously between a given dyad. Most grooming bouts were dyadic; bouts involving more than two individuals (only $1 \%$ of the total sample) are excluded. Calculations of the frequency of grooming are based on all grooming events recorded from identified individuals in each field season. Here we consider only grooming records from mature (adult and adolescent) residents and do not include grooming dyads between immatures or matures and immatures respectively. Calculations of the duration of grooming bouts and reciprocity are restricted to those records in which beginning and end were seen. Reciprocity within a given bout refers to the relative time each participant spends grooming the other and is expressed by values ranging between $100 \%$ (perfect reciprocity) and 0\% (unidirectional grooming).

\section{Statistics}

For statistical analyses the following tests and programmes were used: (1) Parentage analyses: CERVUS (Marshall et al., 1998); (2) Spatial associations: Randomisation programme by Lamprecht \& Hofer (more details are given above in the according section) and KolmogorovSmirnov test (Siegel \& Castellan, 1988); (3) Social grooming: $U$-test, Fisher's exact test, Mantel-Haenszel test, Kolmogorov-Smirnov test, $X^{2}$ test and $X^{2}$ goodness of fit (Sokal \& Rohlf, 1981; Siegel \& Castellan, 1988). All probabilities are two tailed.

\section{Results}

The results from the genetic typings, together with the demographic information from the field observations reveal a clear picture of the intra-group relationships (Figs 1 and 2). All mother-offspring pairs that had already been identified on the basis of behavioural criteria (e.g. nursing, carrying, nest sharing, Figs 1 and 2) were confirmed by genetic data. In seven cases, we could identify a single matching father for such pairs (see Fig. 2). For most adolescent and adult males a matching mother was found while this was not the case for most females, indicating that the latter leave the community during early adolescence (Gerloff et al., 1999). In view of the high rate of exogamy, all parent-offspring, sibling and half-sibling relationships are in the following considered as close kin, while all others are considered as unrelated. 


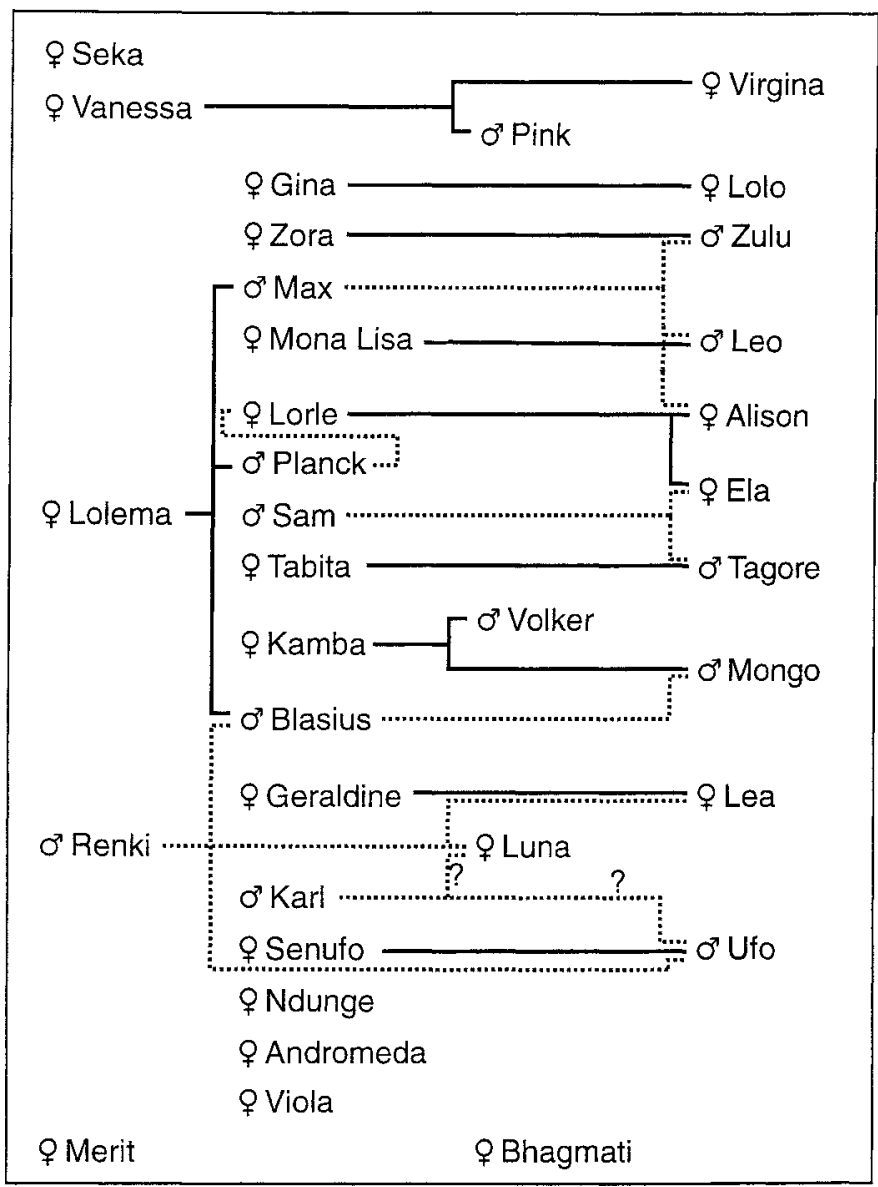

Fig. 2. Genealogy of the Eyengo community: maternal relatives are connected by solid lines; paternal relatives are connected by dotted lines; question marks indicate cases in which two males could not be excluded as fathers.

\section{Spatial associations}

Analyses of associations between community members was derived from party membership. Spatial association between mother and dependent offspring (up to about seven years) are excluded here and the following results refer only to associations between adult and adolescent individuals. Table 1 shows the number of dyads of each association class per field season based on comparison of the observed frequencies of association with the expected values of association derived from randomisation. 'Separatists' accounted 
TABLE 1. Frequency of types of dyadic associations observed during four field seasons

\begin{tabular}{lrrrr}
\hline Type of association & 1993 & 1994 & 1995 & 1996 \\
\hline 'Separatists' & 4 & 2 & 3 & 0 \\
Random associates & 306 & 213 & 232 & 166 \\
Close associates & 15 & 16 & 18 & 24 \\
$\quad$ male-male close associates & 1 & 3 & 3 & 1 \\
$\quad$ male-female close associates & 8 & 9 & 10 & 13 \\
$\quad$ female-female close associates & 6 & 4 & 5 & 10 \\
Possible dyads among close kin & 11 & 6 & 6 & 4 \\
Close associates among close kin & 3 & 5 & 4 & 2 \\
Possible dyads among unrelated & 314 & 225 & 247 & 186 \\
Close associates among unrelated & 12 & 11 & 14 & 22 \\
\hline
\end{tabular}

Figures refer only to dyadic associations among adult/adolescent individuals.

for the smallest number of dyads ( $0-4$ dyads per field season). In most cases, association indices did not diverge significantly from the values computed by the randomisation programme, that is, association was random. However, each field season some community members associated significantly more often than expected, that is, close association (Table 1). In each field season close associations between males and females accounted for the largest proportion $(>50 \%)$ of the total score, followed by female-female dyads (range: 25-41\%) and male-male dyads (range: 4-19\%).

Application of information on genetic relatedness to the data on spatial associations showed that all 'separatists' were unrelated individuals. Relatives were more often involved in close association dyads than expected (Kolmogorov-Smirnov test, $D=1.0814, p<0.01$, Table 1) and long-term associations lasting for more than two field seasons existed only between two mother-son pairs (Table 2). In two cases close associations between adult males ended when one individual disappeared from the community (Table 2). Four out of eight close associations between males involved half sibs (Max-Planck in 1994 and 1995, Max-Blasius in 1995, Planck-Blasius in 1994). Close associations between unrelated individuals occurred less frequently than expected (Kolmogorov-Smirnov test, $D=0.2055, p<0.05$, Table 1) and, considering the frequent changes in partnership, appeared to be short-term and opportunistic. Associations between females involved all mature resident females. Associations did usually not exceed one field season and were characterised by frequent changing partner combinations. The 
TABLE 2. Close associations between the same individuals lasting for two field seasons or longer

\begin{tabular}{llllll}
\hline Dyad & Sex & 1993 & 1994 & 1995 & 1996 \\
\hline Max-Karl & $\mathrm{m}-\mathrm{m}$ & $\mathrm{x}$ & $\mathrm{x}$ & $*$ & \\
Max-Gina & $\mathrm{m}-\mathrm{f}$ & $\mathrm{x}$ & $\mathrm{x}$ & & \\
Max-Tabita & $\mathrm{m}-\mathrm{f}$ & $\mathrm{x}$ & $\mathrm{x}$ & & \\
Volker-Kamba & $m-f$ & $x$ & $x$ & $x$ & $x$ \\
Pink-Vanessa & $m-f$ & $x$ & $x$ & $x$ & $*$ \\
Max-Planck & $\mathrm{m}-\mathrm{m}$ & & $\mathrm{x}$ & $\mathrm{x}$ & $\mathrm{x}$ \\
Planck-Zora & $\mathrm{m}-\mathrm{f}$ & & & $\mathrm{x}$ & $\mathrm{x}$ \\
Kamba-Ndunge & $\mathrm{f}-\mathrm{f}$ & & & & \\
\hline
\end{tabular}

* = one member of this dyad disappeared; italics refer to dyads between mother and mature son.

only exception was the close association between two adult females Kamba and Ndunge which lasted for at least two field seasons (Table 2). Qualitative assessments suggest that older females were more often involved in close associations with other females than adolescent and young adult females. During the study period reported on here, five females gave birth (Fig. 1). Out of that, four did not associate closely with other females for the following field seasons while one did continuously associate with residents of both sexes.

During the first three field seasons most mixed-sex close associations between unrelated individuals involved the alpha male (Max). In the last season (1996) when this individual had disappeared, the number of mixedsex close associations increased (Table 1) and associations were more evenly distributed among the resident males.

\section{Social grooming}

In order to evaluate the impact of association patterns and relatedness on the distribution of grooming we first assigned the total number of grooming bouts recorded in a given field season proportionally to the number of dyads available in the same field season. Comparison of these expected values with observed frequencies revealed that close associates groomed each other significantly more often than expected ( $X^{2}$ goodness of fit, $p<0.001$, Fig. 3) while random associates groomed each other as often as expected (Fig. 3). In two field seasons (1993 and 1996) did the opposing trends of both categories 


\section{grooming frequency}

close associates
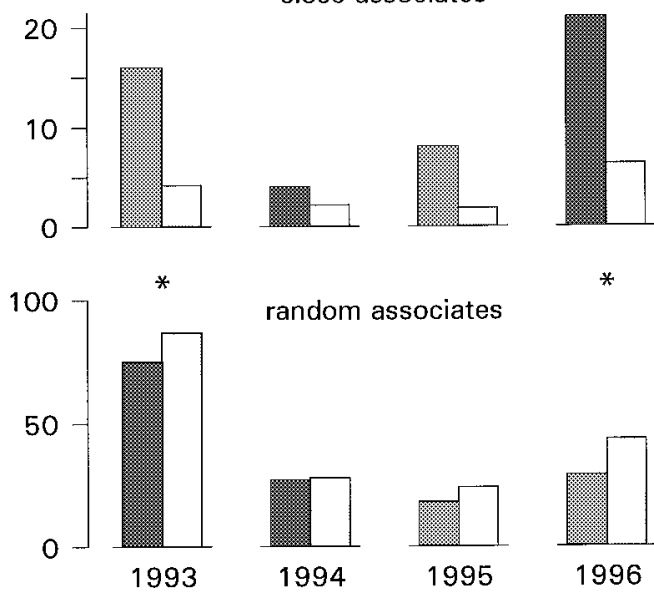

random associates

*
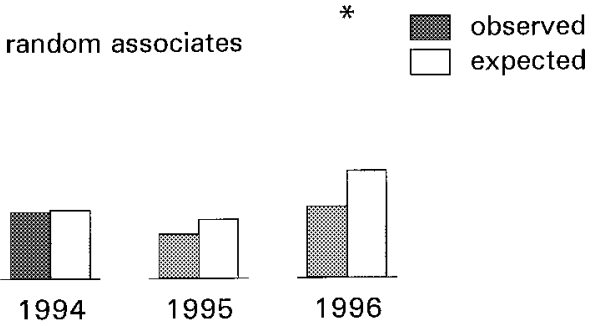

Fig. 3. Frequency of dyadic grooming bouts of close associates versus random associates. Scales show the absolute number of grooming bouts recorded. Asterisks indicate the field seasons in which both categories differed significantly.

TABLE 3. Values refer to grooming bouts were beginning, termination, and changes of grooming direction could be recorded

\begin{tabular}{|c|c|c|c|c|c|}
\hline & & $\begin{array}{l}\text { Close kin } \\
n=17\end{array}$ & $\begin{array}{l}\text { Unrelated } \\
n=119\end{array}$ & $\begin{array}{l}\text { Close } \\
\text { associates } \\
n=26\end{array}$ & $\begin{array}{l}\text { Random } \\
\text { associates } \\
n=105\end{array}$ \\
\hline \multirow{3}{*}{ Duration of grooming bouts $(\mathrm{min})$} & $\bar{x}$ & 14.7 & 14.3 & 26.1 & 11.3 \\
\hline & M & 8.0 & 7.0 & 18.0 & 6.0 \\
\hline & $\mathrm{SD}$ & 14.5 & 16.5 & 20.6 & 13.9 \\
\hline \multirow{3}{*}{ Duration of episodes (min) } & $\bar{x}$ & 4.2 & 4.5 & 5.8 & 3.8 \\
\hline & M & 3.8 & 3.5 & 5.0 & 3.0 \\
\hline & $\mathrm{SD}$ & 3.6 & 3.5 & 2.8 & 3.1 \\
\hline \multirow{3}{*}{ Deviation from reciprocity (\%) } & $\bar{x}$ & 56.3 & 64.1 & 36.2 & 69.3 \\
\hline & M & 50.0 & 85.0 & 23.2 & 100.0 \\
\hline & $\mathrm{SD}$ & 39.0 & 38.6 & 33.5 & 37.3 \\
\hline
\end{tabular}

(close associates versus random associates) reach a level of significance (Mantel-Haenszel test $p<0.01$ in 1993 and 1996 respectively, Fig. 3). Duration of grooming bouts differed significantly with close associates 


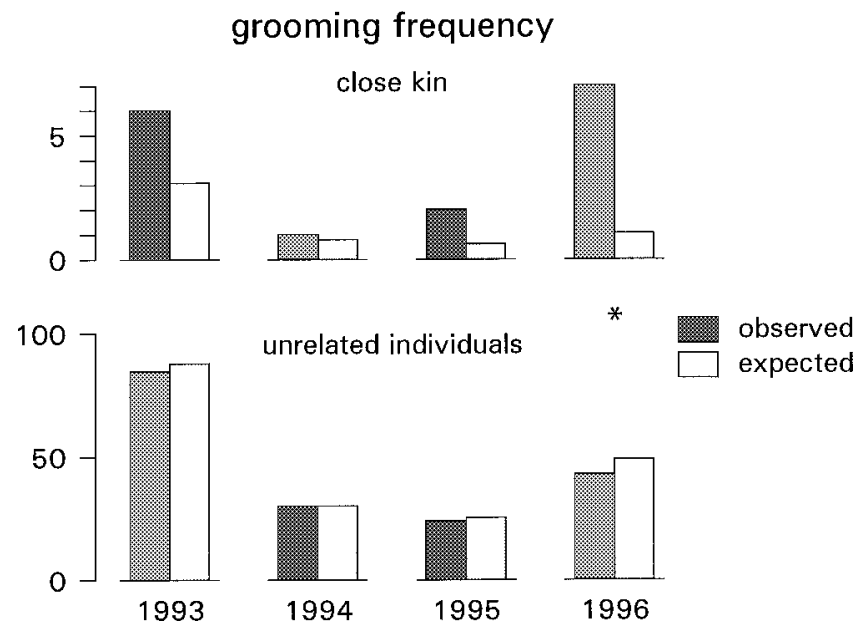

Fig. 4. Frequency of dyadic grooming bouts of close kin versus unrelated individuals. Scales refer to the absolute number of grooming bouts per field season. Asterisk indicates the field season in which both categories differed significantly.

grooming each other for longer times than did random associates (mean $26.1 \mathrm{~min}, \mathrm{SD} 20.6, n=26$ versus $11.3 \mathrm{~min}, \mathrm{SD} 13.9, n=105, U$-test, $p<0.001$, Table 3). Close relatives groomed each other more often than expected (Kolmogorov-Smirnov test, $D=0.653, p<0.01$, Fig. 4), while the frequency of grooming between unrelated individuals was not different from expected values (Kolmogorov-Smirnov test, $D=0.057$, n.s., Fig. 4). Only in one field season (1996) did the difference between these categories (close kin versus unrelated) reach the level of significance (Fishers exact test, $p<0.05)$. Durations of grooming bouts were almost identical for both categories $($ mean $=14.7 \mathrm{~min}, \mathrm{SD} 14.5, n=17$ vs $14.3 \mathrm{~min}, \mathrm{SD} \mathrm{16.5}$, $n=119$, Table 3 ). When 'separatists' were in the same party, they never groomed each other.

Advantages of affiliative relations between unrelated individuals are thought to derive from reciprocation, while affiliation among close kin may be beneficial even in the absence of reciprocity (Hamilton, 1964; Trivers, 1971). Following this assumption, we predicted a higher extent of reciprocity in grooming bouts of unrelated individuals. As a simple strategy to avoid severe deviation from reciprocity, individuals could limit the amount of time they invest in a single grooming episode. Accordingly, we predicted that grooming bouts of unrelated individuals will have shorter episodes than bouts between close kin. However, this is not what we found. Comparing 
complete grooming bouts of unrelated individuals with those of close kin, neither the length of episodes, nor the degree of reciprocity differed significantly (Table 3). Instead we found that among close associates the degree of reciprocity was higher than in bouts involving random associates (median $=100 \%$ vs $23.2 \% U$-test, $p<0.001$, Table 3 ). Also, the average length of episodes was longer in grooming bouts of close associates than in bouts between random associates (median $=3.0 \mathrm{~min}$ vs $5.0 \mathrm{~min}, U$-test, $p<0.001$, Table 3).

\section{Discussion}

Previous studies on bonobos have emphasised the gregariousness of females (Kuroda, 1979; Badrian \& Badrian, 1984). In a captive study, female group members associated with each other more often than with males and their affiliative relations closely resembled those of species with female philopatry (Parish \& de Waal, in review). Earlier studies at Lomako also reported that affiliation among females was more apparent than between the sexes (White, 1988). This contrasts with our data and with data from another field site, Wamba (Furuichi \& Ihobe, 1994; Furuichi, 1997) which show close spatial associations and strong social bonds between males and females. In our study, male-female dyads accounted for the largest proportion of close associations, and most of the long-term associations lasting for several consecutive field seasons were of mixed-sex constituency. With one exception, 'separatists' were always female-female dyads, and for several field seasons, the two highest ranking females (Kamba and Zora) were in this category. The data on social grooming make it seem unlikely that the patterns of dyadic spatial associations were caused by attraction to a third individual or by an external factor (e.g. food source, resting site). Close associates groomed each other more often than expected, grooming bouts lasted longer, and reciprocity within a given bout exceeded that of bouts involving random associates. Moreover, 'separatists' travelling in the same party never groomed each other. From the absence of affiliative behaviour between 'separatists' one could interpret the low rate of spatial association between these individuals as the result of active avoidance. However, such a conclusion would require detailed accounts on dynamics of their fissionfusion patterns. 
Molecular analyses of the genetic relatedness between community members demonstrate that the strong social bonds between mature males and females were partly related to kinship. High association indices were most consistent between mother-son pairs and between adult half-sibs. There was no evidence for mating between mothers and their adult sons and some of the mixed-sex close associations involved females who had given birth in the same year and, therefore, did not show any mating activities. Thus, in contrast to previous assertions (e.g. Thompson-Handler et al., 1984; Kano, 1989), the affinity between male and female bonobos is not always based on sexual attraction. Adult males associate and affiliate with adult females outside the context of matings.

So, what are the benefits derived from such cross-sexual bonds? It may be that such alliances are important for rank acquisition. In chimpanzees, males are dominant over females and a male's rank depends on both physical traits and support from male allies who are often close kin (Riss \& Goodall, 1977; Nishida, 1983; Goodall, 1986). In bonobos dominance relations appear to be egalitarian (de Waal, 1995). Data from Wamba and Lomako suggest that in bonobos, male alliances are weakly developed and that male-male conflicts mostly involve agonistic displays without physical aggression (Furuichi $\&$ Ihobe, 1994, own data). In the absence of severe physical aggression, alliances with adult females may be as effective as those with adult males (Furuichi, 1997). Thus, the lasting bonds between mothers and sons may be a substitute for male coalitions serving rank acquisition in chimpanzees.

Differences in rank are expected to have reproductive consequences. At Wamba mating success was found to be positively correlated with rank (Kano, 1996) and at Lomako, the two highest ranking males were particularly successful in fathering offspring (Gerloff et al., 1999). More data are needed to demonstrate the impact of mothers on the rank of their adult sons. However, if reproductive success increases with rank and if mothers are able to support their sons in conflicts with other community members, then close associations and affiliative relations would be beneficial for both sexes. If mothers are able to effectively support their adult sons, then unrelated females also have the potential to provide similar aid. In conflicts between resident males physical aggression is usually rare and the two opponents and their female allies mainly engage in motoric displays. Thus, support of a resident male is likely to entail costs to the female and, therefore, is expected to vary with the nature of conflict and identity of the individuals involved. 
For example, preliminary data from Lomako suggest that females support males only in conflicts with other males but not during agonistic encounters with females (unpublished data). While mothers who support their sons are likely to benefit via inclusive fitness, unrelated females could also gain from promotion of males. Close spatial associations and affiliative relations cannot be enforced by the male but instead depend on female cooperation. Agonistic dominance behaviour by the male against his female ally would probably end the relation. As a result females who engage in alliances with unrelated males are unlikely to be dominated by these males, in spite of sexual dimorphism. Reduced or even absent male dominance decreases competition for food and other limited resources essential for the reproductive success of females. However, the available information on the dynamics of social status in male bonobos are largely anecdotal and more systematic data are required to test the impact of females' support on changes in rank of resident males.

Permanent associations between male and female primates may also serve protection against infanticide or harassment of females by other males (Wrangham, 1979 and 1986; van Schaik, 1996; van Schaik \& Kappeler, 1997; Sterck et al., 1997). It may be that strong bonds between related individuals serve the same function. By protecting a younger half-sibling against infanticide, adult sons would benefit via inclusive fitness. Moreover, spatial associations between mothers and sons persist at times of food scarcity when females who have no adult sons often travel alone. Thus, mothers with adult sons have potential protection at times when females with dependent offspring are most vulnerable. During intercommunity encounters, aggressive interactions are not uncommon but are mainly restricted to agonistic displays (Kano, 1992; own data). However, recent observations at Lomako suggest that severe aggression does occur when mixed-sex parties encounter unknown males. In October 1997, two strange adult males appeared in the home range of the Eyengo community. Whenever they ate or nested nearby, they were charged by resident males and females. Males appeared to be more active in, and spend more time with chasing the strange males than females did. Although the two strangers acted submissively most of the time, the attacks of the resident males showed severe physical aggression. This indicates that, unlike encounters with parties from a neighbouring community, intruding males may pose a strong threat. Without data on the long-term consequences of intraspecific violence, the role of males as protectors of females and their offspring remains speculative. Long-term field studies on wild bonobos at 
Lomako and Wamba have not yet provided any evidence for infanticide and the causes of mortality of older individuals remain largely unknown. Until this aspect of social life is explored in more detail, our knowledge of the functional significance of patterns of association and social bonding among bonobos remains incomplete.

\section{References}

Badrian, A.J. \& Badrian, N.L. (1984). Group composition and social structure of Pan paniscus in the Lomako Forest. - In: The pygmy chimpanzee (R.L. Susman, ed.). Plenum Press, New York, p. 325-346.

Badrian, N.L. \& Malenky, R.K. (1984). Feeding ecology of Pan paniscus in the Lomako Forest, Zaïre. - In: The pygmy chimpanzee (R.L. Susman, ed.). Plenum Press, New York, p. 275-299.

Bygott, J.D. (1979). Agonistic behavior, dominance, and social structure in wild chimpanzees of the Gombe National Park. - In: The great apes (D.A. Hamburg \& E.R. McCown, eds). Benjamin/Cummings, Menlo Park, CA, p. 405-427.

Estroup, A., Largiader, C.R., Perrot, E. \& Chourrout, D. (1996). Rapid one-tube DNA extraction for reliable PCR detection of fish polymorphic markers and transgenes. Mol. Marine Biol. Biotechn. 5, p. 295-298.

Fruth, B. \& Hohmann, G. (1994). Comparative analyses of nest building behavior in bonobos and chimpanzees. - In: Chimpanzee cultures (R.W. Wrangham, W.C. McGrew, F.B. de Waal \& P.G. Heltne, eds). Harvard University Press, Cambridge, p. 109-128.

Furuichi, T. (1989). Social interactions and the life history of female Pan paniscus in Wamba, Zaïre. - Int. J. Primatol. 10, p. 173-197.

— - (1997). Agonistic interactions and matrifocal dominance rank of wild bonobos (Pan paniscus) at Wamba. — Int. J. Primatol. 18, p. 855-875.

— — \& Ihobe, H. (1994). Variation in male relationships in bonobos and chimpanzees. — Behaviour 130, p. 211-228.

Gerloff, U., Hartung, B., Fruth, B., Hohmann, G. \& Tautz, D. (1999). Intracommunity relationship, dispersal pattern and paternity success in a wild living community of bonobos (Pan paniscus) determined from DNA analysis of faecal samples. - Proc. R. Soc. Lond. B 266, p. 1189-1195.

— - Schlötterer, C., Rassmann, K., Rambold, I., Hohmann, G., Fruth, B. \& Tautz, D. (1995). Amplification of hypervariable simple sequence repeats (microsatellites) from excremental DNA of wild living bonobos (Pan paniscus). — Mol. Ecol. 4, p. 515-518.

Goldberg, T.L. \& Wrangham, R.W. (1997). Genetic correlates of social behaviour in wild chimpanzees: evidence from mitochondrial DNA. - Anim. Behav. 54, p. 559-570.

Goodall, J. (1986). The chimpanzees of Gombe: patterns of behavior. — The Belknap Press of Harvard University Press, Cambridge, Mass.

Grinnell, J., Packer, C. \& Pusey, A.E. (1995). Cooperation in male lions: kinship, reciprocity or mutualism? - Anim. Behav. 49, p. 95-105.

Gyapay, G., Morissette, J., Vignal, A., Dib, C., Fizames, C., Millasseau, P., Marc, S., Bernardi, G., Lathrop, M. \& Weissenbach, J. (1994). The 1993-94 Généthon human genetic linkage map. — Nat. Gen. 7, p. 246-339. 
Hamilton, W.D. (1964). The genetical evolution of social behaviour. - J. theor. Biol. 7, p. $95-105$.

Hashimoto, C. (1997). Context and development of sexual behavior of wild bonobos (Pan paniscus) at Wamba, Zaïre. - Int. J. Primatol. 18, p. 1-21.

_ — Furuichi, T. \& Takenaka, O. (1996). Matrilineal kin relationship and social behavior of wild bonobos (Pan paniscus): sequencing the D-loop region of mitochondrial DNA. Primates 37, p. 305-318.

Kano, T. (1982). The social group of pygmy chimpanzees (Pan paniscus) of Wamba. Primates 23, p. 171-188.

— - (1989). The sexual behavior of the pygmy chimpanzees. — In: Understanding Chimpanzees (P.G. Heltne \& L.A. Marquardt, eds). Harvard University Press, Cambridge, p. 176-183.

— - (1992). The last ape: Pygmy chimpanzee behavior and ecology. — Stanford University Press, Stanford, CA.

- - (1996). Male rank order and copulation rate in a unit-group of bonobos at Wamba, Zaïre. - In: Great ape societies (W.C. McGrew, L.F. Marchant \& T. Nishida, eds). Cambridge University Press, Cambridge, p. 135-143.

Kuroda, S. (1979). Grouping of the pygmy chimpanzees. - Primates 20, p. 161-183.

Lamprecht, J. (1985). Distress call alternation in hand-reared goslings (Anser indicus): vocal co-operation between siblings? - Anim. Behav. 33, p. 839-848.

Marshall, T.C., Slate, J., Kruuk, L. \& Pemberton, J.L. (1998). Statistical confidence for likelyhood-based paternity inference in natural populations. - Mol. Ecol. 7, p. 639655.

McGrew, W.C., Marchant, L.F. \& Nishida, T. (1996). Great ape study sites. — In: Great ape societies (W.C. McGrew, L.F. Marchant \& T. Nishida, eds). Cambridge University Press, Cambridge, p. 309-319.

Nishida, T. (1983). Alpha status and agonistic alliance in wild chimpanzees (Pan troglodytes schweinfurthii). - Primates 24, p. 318-336.

— - Takasaki, H. \& Takahata, Y. (1990). Demography and reproductive profiles. — In: The chimpanzees of the Mahale Mountains (T. Nishida, ed.). Tokyo University Press, Tokyo, p. 63-97.

Noreen, E.W. (1989). Computer intensive methods for testing hypotheses. — John Wiley \& Sons, New York.

Packer, C. (1977). Reciprocal altruism in Papio anubis. - Nature 265, p. 441-443.

Parish, A.R. (1996). Female relationships in bonobos (Pan paniscus). Evidence for bonding, cooperation, and female dominance in a male-philopatric species. - Hum. Nat. 7, p. 6196.

Press, W.H., Teukolsky, S.A., Vetterling, W.T. \& Flannery, B.P. (1992). Numerical recipes in Fortran. The art of scientific computing. - Cambridge University Press, Cambridge, 2nd ed.

Pusey, A.E. (1980). Inbreeding avoidance in chimpanzees. - Anim. Behav. 28, p. 543-552.

— - Williams, J. \& Goodall, J. (1997). The influence of dominance rank on the reproductive success of female chimpanzees. - Science 277, p. 828-830.

Riss, D. \& Goodall, J. (1977). The recent rise to the alpha rank in a population of free-ranging chimpanzees. - Folia Primatol. 27, p. 134-151.

Rood, J.P. (1990). Group size, survival, reproduction and routes to breeding in dwarf mongooses. - Anim. Behav. 39, p. 566-572. 
Siegel, S. \& Castellan, N.J. (1988). Nonparametric statistics for the behavioral sciences. 2nd ed. - McGraw Hill, New York.

Sokal, R.R. \& Rohlf, F.J. (1981). Biometry, 2nd ed. - W.H. Freeman, San Francisco.

Sterck, E.H.M., Watts, D.P. \& van Schaik, C.P. (1997). The evolution of female social relationships in nonhuman primates. - Beh. Ecol. Sociobiol. 41, p. 291-309.

Szalay, F.S. \& Costello, R.K. (1991). Evolution of permanent estrus displays in hominids. J. Hum. Evol. 20, p. 439-464.

Thompson-Handler, N., Malenky, R.K. \& Badrian, N. (1984). Sexual behavior of Pan paniscus under natural conditions in the Lomako forest, Equateur, Zaïre. - In: The pygmy chimpanzee (R.L. Susman, ed.). Plenum Press, New York, p. 347-368.

Trivers, R. (1971). The evolution of reciprocal altruism. - Q. Rev. Biol. 46, p. 35-57.

Turke, P.W. (1984). Effects of ovulatory concealment and synchrony on protohominid mating systems and parental roles. - Ethol. Sociobiol. 5, p. 33-44.

van Schaik, C.P. (1983). Why are diurnal primates living in groups? - Behaviour 87, p. 120144.

— — (1989). The ecology of social relationships amongst female primates. — In: Comparative socioecology (V. Standen \& R.A. Foley, eds). Blackwell, Oxford, p. 195-218.

- - (1996). Social evolution in primates: The role of ecological factors and male behaviour. — Proc. British Acad. 88, p. 9-31.

— — \& Kappeler, P.M. (1997). Infanticide risk and the evolution of male-female association in primates. - Proc. R. Soc. Lond. B 264, p. 1687-1694.

de Waal, F.B. (1995). Bonobo sex and society. - Scient. Amer. 272 (3), p. 82-88.

White, F.J. (1988). Party composition and dynamics in Pan paniscus. — Int. J. Primatol. 9, p. 179-193.

— — \& Wrangham, R.W. (1988). Feeding competition and patch size in the chimpanzee species Pan paniscus and Pan troglodytes. - Behaviour 105, p. 148-164.

Wrangham, R.M. (1979). On the evolution of ape social systems. - Soc. Sci. Inf. 18, p. 334368.

- - (1986). Ecology and social relationship in two species of chimpanzees. - In: Ecological aspects of social evolution (D.I. Rubenstein \& R.W. Wrangham, eds). - Princeton University Press, Princeton, NJ, p. 352-478. 